\title{
Predisposition to Graves' Disease and Graves' Ophthalmopathy by Genetic Variants of IL2RA
}

\author{
Juan $\mathrm{Du}^{1}$, Xin Wang ${ }^{1}$, Guiqin Tan ${ }^{1}$, Wenwen Wei ${ }^{1}$, Fangyu Zhou ${ }^{1}$, Zhongzhi Liang ${ }^{1}$, Hua \\ $\mathrm{Li}^{2}$, and Hongsong $\mathrm{Yu}^{1}$ \\ ${ }^{1}$ Zunyi Medical University \\ ${ }^{2}$ Chongqing Medical University
}

May 14, 2020

\begin{abstract}
Previous studies have identified that Th17/Treg cells were involved in Graves' disease (GD). This study aimed at clarifying the association between GD susceptibility and single nucleotide polymorphisms (SNPs) of Th17/Treg cells-related genes, including IL2RA, miR27a, miR182, and FoxO1. A two-stage association study was performed in 650 GD patients and 1300 healthy controls. PCR-RFLP assays, real-time PCR and ELISA were performed. The result demonstrated that significantly increased frequencies of IL2RA/rs3118470 TT genotype $(\mathrm{Pc}=2.212 \times 10-3)$ and IL2RA/rs2104286 AA genotype $(\mathrm{Pc}=1.754 \times 10-5)$ were observed in GD. Stratification analysis also revealed that rs3118470 TT genotype and rs2104286 AA genotype were associated with Graves' ophthalmopathy (GO) susceptibility $(\mathrm{Pc}=1.848 \times 10-6, \mathrm{Pc}=1.230 \times 10-3$, respectively). Functional studies showed that carriers of the rs2104286 AA genotype had lower IL2RA mRNA expression than AG genotype carriers $(\mathrm{P}=0.021)$. Cytokine analyses revealed that carriers with the rs3118470 risk genotype had decreased anti-inflammatory cytokine levels (IL-10 and TGF- $\beta 1$ ) and increased IL-17 secretion than protective genotype individuals $(\mathrm{P}<0.05)$. For the rs2104286 locus, AA genotype individuals had lower IL-10 levels $(\mathrm{P}=0.015)$ and increased IL-17 levels than AG genotype carriers $(\mathrm{P}=1.467 \times 10-4)$. In conclusion, our findings suggested that IL2RA/ (rs3118470, rs2104286) were associated with GD and GO susceptibility in Southwest Chinese Han population.
\end{abstract}

\section{ABSTRACT}

Previous studies have identified that Th17/Treg cells were involved in Graves' disease (GD). This study aimed at clarifying the association between GD susceptibility and single nucleotide polymorphisms (SNPs) of Th17/Treg cells-related genes, including IL2RA, miR27a, miR182, and FoxO1 .A two-stage association study was performed in 650 GD patients and 1300 healthy controls.PCR-RFLP assays, real-time PCR and ELISA were performed. The result demonstrated thatsignificantly increased frequencies of IL2RA / rs3118470 TT genotype $\left(P c=2.212 \times 10^{-3}\right)$ and $I L 2 R A / \mathrm{rs} 2104286$ AA genotype $\left(P c=1.754 \times 10^{-5}\right)$ were observed in GD. Stratification analysis also revealed that rs3118470 TT genotype and rs2104286 AA genotype were associated with Graves' ophthalmopathy (GO) susceptibility $\left(P c=1.848 \times 10^{-6}, P c=1.230 \times 10^{-3}\right.$, respectively). Functional studies showed that carriers of the rs2104286AA genotypehad lower IL2RA mRNA expression than AG genotype carriers $(P=0.021)$. Cytokine analyses revealed that carriers with the rs3118470 risk genotype had decreased anti-inflammatory cytokine levels (IL-10 and TGF- $\beta 1$ ) and increased IL-17 secretion than protective genotype individuals $(P<0.05)$. For the rs2104286 locus, AA genotype individuals had lowerIL-10 levels $(P=0.015)$ and increased IL-17 levels than AG genotype carriers $\left(P=1.467 \times 10^{-4}\right)$. In conclusion, our findings suggested that IL2RA / (rs3118470, rs2104286) were associated with GD and GO susceptibility in Southwest Chinese Han population.

Keywords: Graves' disease, genetic susceptibility,IL2RA, miR27a, miR182 , FoxO1 


\section{INTRODUCTION}

Graves' disease (GD), also known as toxic diffuse goiter, is one of the most common autoimmune thyroid diseases (AITDs), which accounts for more than $85 \%$ of all clinical types of hyperthyroidism (Xiaoheng et al., 2017). GD occurs in women aged 30-50 years (Veneti et al., 2019), and it affects approximately 1\% of the world's population (J. Li, Teng, Yu, Hou, \& Shan, 2019). The ratio of male to female patients is approximately 1:5-1:10 (Liang et al., 2015). Approximately 50\% of GD patients can develop Graves' ophthalmopathy (GO), and severe stages can affect vision (Longo \& Higgins, 2019). Immunologically, GD is characterized by an increased level of circulating thyroid stimulating antibody (TSAb) against thyroidstimulating hormone receptor (TSHR), thyroglobulin ( $\mathrm{Tg}$ ) and thyroid peroxidase (TPO), leading to diffuse thyroid enlargement and hyperthyroidism (Fang et al., 2015). The pathogenesis of GD has not yet been fully elucidated, but it is generally believed that the occurrence of GD is the interaction result of genetic susceptibility and environmental factors (Chen et al., 2018).

Studies have shown that the coincidence rate of GD in identical twins was 50\%-70\%, while the coincidence rate of GD in fraternal twins was 3\%-25\% (Hwangbo \& Park, 2018). Twin studies have indicated that the genes account for $79 \%$ of the role in predisposition to GD (Lane et al., 2019). Extensive genetic association studies have identified that many genes are associated with predisposition to GD, for example, human leukocyte antigen (HLA ), cytotoxic T-lymphocyte-associated antigen-4 (CTLA4), protein tyrosine phosphatase 22 (PTPN22), Fc receptor like 3 (FCRL3), thyroid stimulating hormone receptor (TSHR), and vitamin D receptor gene (VDR ) (Mehraji et al., 2017; Chu et al., 2018; Ting et al., 2016; Li et al., 2017; Khong et al., 2016; Fujii et al., 2017; M. Planck, Shahida, Malm, \& Manjer, 2018 ). At present, antithyroid drugs are regarded as the preferred methods to treat GD in China, but recurrence within two years after retreat of the drug is as high as $50 \%-60 \%$ ( J. Li, Sun, Yao, \& Xia, 2018). Therefore, it is necessary to elucidate the pathogenesis of GD.

Studies have recognized that $\mathrm{T}$ helper 17 (Th17) cells and Regulatory $\mathrm{T}$ (Treg) cells are involved in the pathogenesis GD. The proportion of Th17 cells and the expression of related genes (IL17 mRNA and POP$\gamma \tau$ mRNA) were increased in patients with GD compared with healthy individuals, and the number of Th17 cells was directly proportional to TSAb, whereas the number of Treg cells and the relatedFoxP3 mRNA expression were lower in GD patients than in normal controls (Qin et al., 2017). The human IL2RA gene located on the chromosome 10 (10p15-p14), encoded the IL-2RA protein and constitutively expressed on the Treg cell surface, which is essential for mediating both the generation of Treg and the maintenance of immune tolerance (Wang \& Chen, 2018). In the context of $\mathrm{CD} 4^{+}$T-cell differentiation, FoxO proteins promote the expression of FoxP3genes essential for the generation and function of Tregs. In addition, FoxO1 can directly inhibit the differentiation of Th17 by binding to the transcription factor ROR $r$ (Harada et al., 2010; Laine et al., 2015). MiR27a andmiR182 can target the 3'UTR of FoxO1, suppressing FoxO1 expression (Guttilla \& White, 2009; Wang et al., 2019). A previous study showed that the frequencies of the IL2RA/ rs3118470 C allele and the CC genotype were higher in the patients with a family history of alopecia areata in a Chinese population (Miao et al., 2013). It has been reported that the IL2RA/ rs2104286 G allele and the GG genotype increased the risk of multiple sclerosis (Xia, Qin, \& Zhao, 2018). An analysis showed that miR27a/ rs895819 contributed to the occurrence of gastric cancer under a co-dominant model in the Chinese population (Yun et al., 2019). Previous studies have identified that the frequency of themiR182 /rs76481776 CT/TT genotype was increased in patients with Vogt-Koyanagi-Harada(VKH) syndrome and Behcet's disease, and increased expression of miR-182 in CT/TT cases compared with that in CC cases in anti-CD3 and anti-CD28 antibodies stimulated CD4 ${ }^{+} \mathrm{T}$ cells (Yu, Liu, Bai, Kijlstra, \& Yang, 2014). TheFoxO1/rs2297626 A allele and the AA genotype showed significantly increased frequencies in acute anterior uveitis patients with ankylosing spondylitis (Yu, Liu, Zhang, et al., 2014). The FoxO1 /rs17592236 located in 3'-UTR of the FoxO1 gene and the identified Ars17446614-Crs17592236 haplotype were associated with an increased risk of diabetic nephropathy (Ma et al., 2019). Considering these studies, we selected nine SNPs in Th17/Treg cells-related genes, including IL2RA, miR27a, miR182, and FoxO1, to explore the association between gene polymorphisms and GD susceptibility in Southwest Chinese Han population. Our results showed that IL2RA gene, but not miR27a, miR182, and FoxO1, contributed to the predisposition 
of GD.

\section{MATERIALS AND METHODS}

\section{Study subjects}

A total of 650 patients with GD and 1300 healthy controls were enrolled in this study.

Diagnosis of GD and GO according to clinical symptom and thyroid hormone level based on American thyroid association guidelines (Ross et al., 2016). Healthy volunteers were recruited from the same region, and they did not have any other autoimmune disease and were matched for sex and age with the patients with GD. The study was registered in the Chinese clinical trial registry (ChiCTR1900022398) and was approved by the Zunyi Medical University Ethics Committee (18-ZY-001). All of the procedures were in accordance with the declaration of Helsinki.

\section{Selection of single nucleotide polymorphisms (SNPs)}

Based on the available literature studies, we selected nine SNPs, which were earlier shown to be associated with a variety of autoimmune diseases (Miao et al., 2013; Xia, Qin, \& Zhao, 2018; Yun et al., 2019; Yu, Liu, Bai, Kijlstra, \& Yang, 2014; Yu, Liu, Zhang, et al., 2014; Ma et al., 2019). Finally, we selected three SNPs (rs3118470, rs2104286, and rs7093069) for IL2RA, one SNP (rs895819) for miR27a,one SNP (rs76481776) for miR182, and four SNPs (rs2297626, rs17592236, rs9549241, and rs12585277) for FoxO1.

\section{Extraction of DNA and genotyping of SNPs}

Genomic DNA obtained was extracted from the peripheral blood of all of the subjects with the QIAamp DNA Blood Mini kit (Qiagen, Valencia, CA, USA). The targeted sequence was amplified by the PCR using appropriate primers(Yu, Liu, Bai, Kijlstra, \& Yang, 2014).Genotyping of the nine SNPs was performed using the polymerase chain reaction restriction fragment length polymorphism (PCR-RFLP) assay. A total of 7 $\mu \mathrm{L}$ PCR product was digested with $3 \mathrm{U}$ of restriction enzyme according to the manufacturer's instructions, involving Pdi-I, DraIII, Rsal, Eco471, BshNI, HindIII, TscAI, Ndel, and BstNI (ThermoFisher Scientific, Waltham, MA, USA) overnight (Table S1). Digestion products were separated on $4 \%$ agarose gels added with goldview I nucleic acid dye (Beijing Solarbio Science \& Technology Co., Ltd., Beijing, China). To confirm the PCR-RFLP genotyping results, we randomly selected a part of the samples to reperform genotyping using direct sequencing.

\section{Peripheral blood mononuclear cell (PBMC) cultures and stimulation}

A total of $5 \mathrm{~mL}$ whole venous blood was collected in ethylene diaminetetraacetic acid (EDTA) anticoagulant vials from the normal controls. PBMCs were isolated and plated in 24-well plates at $1 \times 10^{6}$ per well density on the day of sample collection, and they were cultured using RPMI1640 medium (Gibco, Carlsbad, CA, USA) supplemented with $10 \%$ fetal bovine serum (Gibco, Carlsbad, CA, USA) and 100 U/mL penicillinstreptomycin (Gibco, Carlsbad, CA, USA). Cells were stimulated with the anti-CD3 antibody $(0.5 \mu \mathrm{g} / \mathrm{mL})$ and anti-CD28 $(0.5 \mu \mathrm{g} / \mathrm{mL})$ (Miltenyi Biotec, Palo Alto, CA, USA), and then cultured at $37^{\circ} \mathrm{C}$ in a moist atmosphere containing $5 \% \mathrm{CO}_{2}$ for 72 hours.

\section{RNA isolation and Real-time PCR}

Cells were collected for RNA extraction, and supernatants were collected to detect the cytokine levels. Total RNA was isolated using TRIzol Reagent (Invitrogen, Carlsbad, CA, USA), and reverse transcription was performed using the cDNA synthesis kit according to the manufacturer's instructions (Takara, Dalian, China). Real-time PCR was conducted using BRYT Green. The primers used were as follows: $\beta$ asıı F: 5'-GGATGCAGAAGGAGATCACTG-3', R: 5'-CGATCCACACGGAGTACTT-3'; IL2RA F: 5'ATGGCTGCAACCATGGAGAC-3', R: 5'-TCTGTTCCCGGCT TCTTACC-3'. Real-time PCR parameters were as follows: step one, one cycle at $95^{\circ} \mathrm{C}$ for $10 \mathrm{~min}$; step two, 40 cycles at $95^{\circ} \mathrm{C}$ for $15 \mathrm{~s}, 59^{\circ} \mathrm{C}$ for 1 min; step three, $95^{\circ} \mathrm{C}$ for $15 \mathrm{~s}, 60^{\circ} \mathrm{C}$ for $15 \mathrm{~s}$ and $95^{\circ} \mathrm{C}$ for $15 \mathrm{~s}$. All of the reactions of real-time PCR were performed in triplicate. The relative expression of candidate genes was calculated using the $2^{-\Delta \Delta^{\prime \prime}}{ }^{\top} \operatorname{method}$. 


\section{ELISA assay}

The cytokine levels in supernatants, including IL-6, IL-10, IL-17, and TGF- $\beta 1$, were measured by a commercial DuoSet ELISA kit (R\&D System, Inc., Minneapolis, MN) according to the manufacturer's instructions.

\section{Statistical analysis}

Statistical analyses were performed with IBM SPSS Statistics version 17.0 (SPSS, Inc., Chicago, IL). The chi-square test was used to determine the difference in sex and distributions of allele as well as the genotype frequency between GD patients and normal controls. The risk effect of each SNP was measured by odds ratios $(O R)$ and $95 \%$ confidence intervals $(95 \% \mathrm{CI}) . P$ values were corrected using the Bonferroni correction method considering multiple tests. The corrected $\mathrm{P}(P c)$ value of the allele was $P \times 18$ and $P c$ of the genotype was $P \times 27$ in the first stage, while the $P c$ value of the allele was $P \times 4$ and $P c$ of the genotype was $P \times$ 6 in the second stage and combined study. $P c<0.05$ was defined as indicative of statistical significance. The ttest or Mann-Whitney U test was used to analyze the difference in age, mRNA expression, and cytokine production among various genotypes.

\section{RESULTS}

\section{Clinical Characteristics of GD patients and healthy controls}

A total of 650 GD patients and 1300 healthy controls were recruited in this study. The average age was $38.8 \pm 14.7$ years among GD patients and 40.1 12.6 years among controls. The 650 GD patients included 194 $(29.8 \%)$ males and $456(70.2 \%)$ females. The 1300 healthy controls consisted of $443(34.0 \%)$ males and 857 $(66.0 \%)$ females. No statistical differences were identified between GD patients and healthy controls in age and gender $(P>0.05$; Table 1$)$. The distribution of genotype frequencies of nine SNPs did not deviate from the Hardy-Weinberg equilibrium in the control group of this study.

\section{Allele and genotype frequencies of nine SNPs in the first phase study}

In the first phase, association between nine SNPs in four genes (IL2RA, miR27a, miR182, and FoxO1 ) and susceptibility to GD were investigated in $300 \mathrm{GD}$ cases and 600 healthy controls. Our analysis revealed a correlation of the $I L 2 R A / \mathrm{rs} 3118470 \mathrm{TT}$ genotype with increased GD risk (TT genotype:Pc $=0.027, O R$ $=1.688)$. For the $I L 2 R A / \mathrm{rs} 2104286$ locus, subjects carrying the AA genotype had higher susceptibility to GD $(P c=0.027, O R=1.658)$, while the AG genotype protected against GD $\left(P c=4.617 \times 10^{-3}, O R\right.$ $=0.530$ (Table 2). No association was identified between the remaining seven SNPs (rs7093069, rs895819, rs76481776, rs2297626, rs17592236, rs9549241, and rs12585277) and susceptibility to GD $(P>0.05$; Table S2).

\section{Allele and genotype frequencies of two SNPs in the second phase and combined study}

To further verify the correlation between two loci (rs3118470 and rs2104286) and susceptibility to GD, we genotyped three loci in another 350 GD patients and 700 healthy controls. The result of rs2104286 was consistent with the first stage results (AA genotype: $P c=0.006, O R=1.618$ ), while no association was observed for rs3118470. The combined data showed that the IL2RA /rs3118470 T allele and the TT genotype ( $\mathrm{T}$ allele: $P c=1.490 \times 10^{-3}, O R=1.278$; TT genotype: $P c=2.212 \times 10^{-3}, O R=1.453$ ), and the $I L 2 R A / \mathrm{rs} 2104286 \mathrm{~A}$ allele and the AA genotype (A allele: $P c=0.008, O R=1.322$; AA genotype: $P c$ $=1.754 \times 10^{-5}, O R=1.636$ ) were significantly associated with an increased risk for GD (Table 2). The sequencing results were consistent with the PCR-RFLP genotyping results.

\section{Allele and genotype frequencies in GO patients and controls}

To further verify the relationship between the three candidate genes and susceptibility to GO, we performed a hierarchical analysis. The results showed that the IL2RA /rs3118470 T allele and the TT genotype showed increased frequencies in GO patients than in controls ( $\mathrm{T}$ allele: $P c=4.036 \times 10^{-4}, O R=1.612$; TT genotype: $\left.P c=1.848 \times 10^{-6}, O R=2.178\right)$, whereas the $\mathrm{C}$ allele and the $\mathrm{CT}$ genotype showed decreased frequencies in GO patients (C allele: $P c=4.036 \times 10^{-4}, O R=0.620$; CT genotype: $P c=0.018, O R=0.628$ ). The IL2RA 
$/ \mathrm{rs} 2104286 \mathrm{AA}$ genotype showed an increased frequency in GO patients than in controls $(P c=1.230 \mathrm{x}$ $\left.10^{-3}, O R=1.851\right)$, while the AG genotype showed a decreased frequency in GO patients $\left(P c=9.420 \times 10^{-6}\right.$, $O R=0.348$; Table 3 ).

\section{The effect of SNPs on candidate gene expression}

To explore whether the three loci affect the expression of the corresponding gene mRNA, we tested the biological function of various genetic variants. This was performed by measuring the expression ofIL2RA in anti-CD3 and anti-CD28 antibody stimulated PBMCs obtained from healthy controls since the presence of immunosuppressive drug treatment in GD patients might affect gene expression. Studies revealed that the rs2104286 locus risk AA genotype individuals showed a significantly decreased IL2RA mRNA compared with those with the protective AG genotype $(P=$, Figure 1). No significant difference was observed in the IL2RA mRNA expression among various genotype individuals at the IL2RA /rs3118470 locus in anti-CD3 and anti-CD28 antibody-stimulated PBMC from healthy controls $(P>0.05$, Figure S1).

\section{Expression of cytokines in different genotypes of theIL2RA/rs3118470 locus}

For the rs3118470 locus, the homozygous TT genotype individuals had lower IL-10 and TGF- $\beta 1$ levels and increased IL-17 level than the CC genotype $(P<0.05)$. No significant difference was identified in the IL-6 level among the rs3118470 TT, CT, and CC genotype individuals in anti-CD3 and anti-CD28 antibody stimulated PBMCs $(P>0.05$, Figure 2).

\section{Expression of cytokines in different genotypes of theIL2RA/rs2104286 locus}

A decreased IL-10 level and an increased IL-17 cytokine secretion level were observed in the IL2RA /rs2104286 AA genotype individuals than in the AG genotype individuals $(P<0.05)$, while there was no statistical difference in the TGF- $\beta 1$ cytokine level $(P>0.05)$. There was no significant difference in the IL-6 secretion levels among the IL2RA /rs2104286 AA, AG, and GG genotypes in anti-CD3 and anti-CD28 antibodystimulated PBMC $(P>0.05$; Figure 3$)$.

\section{DISCUSSION}

In this study, we showed that IL2RA /rs3118470 and IL2RA /rs2104286 were associated with GD susceptibility, while the remaining seven loci (rs7093069, rs895819, rs76481776, rs2297626, rs17592236, rs9549241, and rs12585277) were not associated with susceptibility to GD in Southwest Chinese Han population. Stratification analysis revealed that two SNPs (rs3118470 and rs2104286) also contributed to the genetic susceptibility of GO in Southwest Chinese Han population.

GD, a common organ-specific autoimmune disease, is caused by genetic susceptibility and environmental factors, resulting in immune dysfunction among individuals and unregulated thyroid hormone production(Sun et al., 2019; Kahaly, Diana, Kanitz, Frommer, \& Olivo, 2020). The cytokine IL-2 is essential for the differentiation of Treg and maintenance of the suppressive function. Activated effector T cells produce IL-2 and transiently up-regulate IL-2RA, enabling them to respond to IL-2. IL2RA on the effector T cells can reduce its expression through a negative feedback when the cells come to rest (Sun et al., 2019). A protease can cleave off IL2RA on the T cell surface to produce sIL2RA that can be detected in the serum (Cerosaletti et al., 2013).

Studies have shown that the IL2RA mRNA was down-regulated in PBMCs from patients with GD (Ji et al., 2020). A study by Tang et al found that IL2RA/ rs3118470 was highly significantly associated with type 1 diabetes and was highly acetylated in T cells involved in indirect disruption of IL2RA transcription (Tang et al., 2015). Song et al conducted a GWAS study of GD in the Han population in Shanghai and Anhui province of China, and found that theIL2RA / rs3118470 polymorphism was significantly associated with susceptibility to GD in the Chinese Han population at the first phase $(\mathrm{P}=0.019)$, but the significance was lost in the verification stage (Song et al., 2013). Our study found that the IL2RA /rs3118470 TT genotype can increase the GD susceptibility in Southwest Chinese Han population. It should be noted that the P-value of the association between IL2RA /rs3118470 TT genotype and GD susceptibility is relatively large in the first stage 
$(P c=0.024)$, while lack of the association was found in the second phase.Previous study showed thatIL2RA /rs2104286 TT genotype was associated with the risk of multiple sclerosis (MS) (Xia et al., 2018). A latest study by Buhelt et al. reported that MS-associated IL2RA /rs2104286 was associated with the expression of IL2RA in $\mathrm{CD}^{+}$cells but not $\mathrm{CD} 8^{+} \mathrm{T}$ cells, and carriers of the risk genotype had reduced surface expression of IL2RA in post-thymic expanded CD4 ${ }^{+} \mathrm{T}$ cells, CD $39^{+}$Treg cells, and memory cell subsets (Buhelt et al., 2019). Chistiakov et al. found that the IL2RA /rs2104286 polymorphism was not significantly associated with the GD susceptibility of the Russian population (Chistiakov, Chistiakova, Voronova, Turakulov, \& Savost'anov, 2011). Our study identified the IL2RA /rs2104286 AA genotype can significantly increase the GD susceptibility in Southwest Chinese Han population, and the IL2RA mRNA expression in PBMC is relatively reduced for carrier of rs2104286 AA genotype. The reason for the inconsistent results may be due to the different genetic background of people in different regions. Brand et al found that IL2RA /rs7093069 was significantly associated with susceptibility to GD in Caucasian (Brand et al., 2007)., while the results of our study showed thatIL2RA /rs7093069 was not significantly associated with GD susceptibility in Southwest China. Recent clinical studies have indicated that low-dose recombinant IL-2 can reduce the number of Th17 cells in the peripheral blood of systemic lupus erythematosus patients and the disease activity index, while it can increase the number of Treg cells (He et al., 2016).

The miRNA, short and non-coding RNA, acts mainly via targeting and regulation messenger RNAs (Viuff, Skakkebaek, Nielsen, Chang, \& Gravholt, 2019). miR27a and miR182 act on the target molecule,FoxO1 mRNA, and inhibit the expression of FoxO1 (Yang et al., 2014). A previous bioinformatic analysis showed that rs895819 is situated in the terminal loop of the pre-miR27a, suggesting that it may affect the expression of matured miR27a and affinity with target mRNAs (Strafella, 2019). However, Takuseet al. reported that there was no difference in the allele and genotype frequencies of miR27a/rs895819 between GD patients and healthy controls in a Japanese population, and rs895819 variants did not affect the expression levels of hsa-miR-27a-3p in PBMCs (Takuse et al., 2017). Our results showed that there was a lack of association between miR27a / rs895819 variants and susceptibility to GD, which is consistent with the study by Takuse et al. Previous studies have identified that themiR182 /rs76481776 locus was associated with VKH syndrome and Behcet's disease, and rs76481776 variants influenced the gene expression in CD4 ${ }^{+} \mathrm{T}$ cells $(\mathrm{Yu}$, Liu, Bai, Kijlstra, \& Yang, 2014). In contrast, we did not find any correlation betweenmiR182 /rs76481776 variants and GD susceptibility. This inconsistent result may be due to the fact that each disease may have specific risk genes.

FoxO1 in the nucleus promotes FoxP3 expression via binding to the FoxP3 conserved non-coding sequence 1 region and decreasing Th17 cells generation as well as transcription of Th17-related genes, including IL-17A, IL-23R and ROR rt-target genes (Du et al., 2018). The study by Gong et al. and colleagues revealed that FoxO1/rs17592236 was not associated with type 2 diabetes in a Chinese Han population (Gong et al., 2017). Previous studies showed that four SNPs (rs2297626, rs17592236, rs9549241, and rs12585277) were not associated with Behçet's disease and VKH Syndrome in a Chinese Han population (Yu, Liu, Bai, et al., 2014). Similarly, our study showed that FoxO1/ (rs2297626, rs17592236, rs9549241, and rs12585277) were not associated with GD susceptibility in the Chinese Han population. This study is the first to explore FoxO1 gene polymorphisms and GD susceptibility, and therefore, further research is needed to verify this association in large study samples.

There are some potential limitations in this study. First, this study only investigated a limited number of SNPs, and it is possible that other as yet unknown SNPs of candidate genes might participate in the occurrence of GD. In addition, PBMCs, a large-cell population, were used to compare the difference in the mRNA expression among various genotype carriers. Further study is needed in a more purified cell subgroup, such as $\mathrm{CD}^{+}{ }^{+} \mathrm{T}$ cells. Moreover, only the Chinese Han population was enrolled in our study, and thus, it is not certain whether this significant association can be generalized to the other ethnic populations.

In summary, our study identified that IL2RA/rs3118470 and IL2RA/rs2104286 were significantly associated with GD and GO susceptibility in Southwest Chinese Han population, which may be involved in the occurrence of GD and GO by affecting the mRNA expression of IL2RA gene and the cytokine production. 


\section{ACKNOWDLEMENTS}

We would like to thank all patients, healthy volunteers and scientists who contributed to this research.

\section{CONFLICT OF INTERESTS}

The authors declare no conflict of interest.

\section{DATA AVAILABILITY}

All data relevant to the study are included in the article or uploaded as supplementary information.

\section{AUTHOR CONTRIBUTORS}

Yu HS, Wang X and Li H conceived the idea and designed this study. Du J performed the experiment, drafting the manuscript and interpretating the data. Du J, Wan X, Tan GQ, Wei WW, Zhou FY, Liang ZZ, $\mathrm{Li} \mathrm{H}$, and Yu HS revised it critically for important intellectual content. Final approval of the version was submitted by all authors.

\section{REFERENCES}

Xiaoheng, C., Yizhou, M., Bei, H., Huilong, L., Xin, W., Rui, H., . . . Zhiguo, D. (2017). General and Specific Genetic Polymorphism of Cytokines-Related Gene in AITD. Mediators Inflamm, 2017, 3916395. doi:10.1155/2017/3916395.

Veneti, S., Anagnostis, P., Adamidou, F., Artzouchaltzi, A. M., Boboridis, K., \& Kita, M. (2019). Association between vitamin D receptor gene polymorphisms and Graves' disease: a systematic review and meta-analysis. Endocrine, 65 (2), 244-251. doi:10.1007/s12020-019-01902-3.

Li, J., Teng, W., Yu, Y., Hou, X., \& Shan, Z. (2019). Linkage Analysis of the Chromosome 5q31-33 Region Identifies JAKMIP2 as a Risk Factor for Graves' Disease in the Chinese Han Population. Med Sci Monit, 25 , 1439-1451. doi:10.12659/msm.911489.

Liang, C., Du, W., Dong, Q., Liu, X., Li, W., Wang, Y., \& Gao, G. (2015). Expression levels and genetic polymorphisms of interleukin-2 and interleukin-10 as biomarkers of Graves' disease. Exp Ther Med, 9 (3), 925-930. doi:10.3892/etm.2015.2180.

Longo, C. M., \& Higgins, P. J. (2019). Molecular biomarkers of Graves' ophthalmopathy. Exp Mol Pathol, 106, 1-6. doi:10.1016/j.yexmp.2018.11.004.

Fang, W., Zhang, Z., Zhang, J., Cai, Z., Zeng, H., Chen, M., \& Huang, J. (2015). Association of the CTLA4 gene CT60/rs3087243 single-nucleotide polymorphisms with Graves' disease. Biomed Rep, 3 (5), 691-696. doi:10.3892/br.2015.493.

Chen, X., Hu, Z., Liu, M., Li, H., Liang, C., Li, W., . . . Wu, G. (2018). Correlation between CTLA-4 and CD40 gene polymorphisms and their interaction in graves' disease in a Chinese Han population. BMC Med Genet, 19 (1), 171. doi:10.1186/s12881-018-0665-y.

Hwangbo, Y., \& Park, Y. J. (2018). Genome-Wide Association Studies of Autoimmune Thyroid Diseases, Thyroid Function, and Thyroid Cancer.Endocrinol Metab (Seoul), 33 (2), 175-184. doi:10.3803/EnM.2018.33.2.175.

Lane, L. C., Allinson, K. R., Campbell, K., Bhatnagar, I., Ingoe, L., Razvi, S., . . . Mitchell, A. L. (2019). Analysis of BAFF gene polymorphisms in UK Graves' disease patients. Clin Endocrinol (Oxf), 90 (1), 170-174. doi:10.1111/cen.13872.

Mehraji, Z., Farazmand, A., Esteghamati, A., Noshad, S., Sadr, M., Amirzargar, S., . . . Amirzargar, A. (2017). Association of Human Leukocyte Antigens Class I and II with Graves' Disease in Iranian Population. Iran J Immunol, 14 (3), 223-230. doi:IJIv14i3A5. 
Chu, X., Yang, M., Song, Z. J., Dong, Y., Li, C., Shen, M., . . . Huang, W. (2018). Fine mapping MHC associations in Graves' disease and its clinical subtypes in Han Chinese. J Med Genet, 55 (10), 685-692. doi:10.1136/jmedgenet-2017-105146.

Ting, W. H., Chien, M. N., Lo, F. S., Wang, C. H., Huang, C. Y., Lin, C. L., . . . Lee, Y. J. (2016). Association of Cytotoxic T-Lymphocyte-Associated Protein 4 (CTLA4) Gene Polymorphisms with Autoimmune Thyroid Disease in Children and Adults: Case-Control Study.PLoS ONE, 11 (4), e0154394. doi:10.1371/journal.pone.0154394.

Li, M., Beauchemin, H., Popovic, N., Peterson, A., d'Hennezel, E., Piccirillo, C. A., . . . Polychronakos, C. (2017). The common, autoimmunity-predisposing $620 \mathrm{Arg}>$ Trp variant of PTPN22 modulates macrophage function and morphology. J Autoimmun, 79 , 74-83. doi:10.1016/j.jaut.2017.01.009.

Khong, J. J., Burdon, K. P., Lu, Y., Laurie, K., Leonardos, L., Baird, P. N., . . . Craig, J. E. (2016). Pooled genome wide association detects association upstream of FCRL3 with Graves' disease. BMC Genomics, 17 (1), 939. doi:10.1186/s12864-016-3276-z.

Fujii, A., Inoue, N., Watanabe, M., Kawakami, C., Hidaka, Y., Hayashizaki, Y., \& Iwatani, Y. (2017). TSHR Gene Polymorphisms in the Enhancer Regions Are Most Strongly Associated with the Development of Graves' Disease, Especially Intractable Disease, and of Hashimoto's Disease. Thyroid, 27 (1), 111-119. doi:10.1089/thy.2016.0345.

Planck, T., Shahida, B., Malm, J., \& Manjer, J. (2018). Vitamin D in Graves Disease: Levels, Correlation with Laboratory and Clinical Parameters, and Genetics. Eur Thyroid J, 7 (1), 27-33. doi:10.1159/000484521.

Li, J., Sun, X., Yao, D., \& Xia, J. (2018). Elevated Serum IL-17 Expression at Cessation Associated with Graves' Disease Relapse.Int J Endocrinol, 2018 , 5689030. doi:10.1155/2018/5689030.

Qin, J., Zhou, J., Fan, C., Zhao, N., Liu, Y., Wang, S., . . . Teng, W. (2017). Increased Circulating Th17 but Decreased CD4(+)Foxp3(+) Treg and CD19(+)CD1d(hi)CD5(+) Breg Subsets in New-Onset Graves' Disease.Biomed Res Int, 2017 , 8431838. doi:10.1155/2017/8431838.

Wang, X. X., \& Chen, T. (2018). Meta-analysis of the association of IL2RA polymorphisms rs2104286 and rs12722489 with multiple sclerosis risk. Immunol Invest, 47 (5), 431-442. doi:10.1080/08820139.2018.1425699.

Harada, Y., Harada, Y., Elly, C., Ying, G., Paik, J. H., DePinho, R. A., \& Liu, Y. C. (2010). Transcription factors Foxo3a and Foxo1 couple the E3 ligase Cbl-b to the induction of Foxp3 expression in induced regulatory T cells. J Exp Med, 207 (7), 1381-1391. doi:10.1084/jem.20100004.

Laine, A., Martin, B., Luka, M., Mir, L., Auffray, C., Lucas, B., . . . Charvet, C. (2015). Foxo1 Is a T Cell-Intrinsic Inhibitor of the RORgammat-Th17 Program. $J$ Immunol, 195 (4), 1791-1803. doi:10.4049/jimmunol.1500849.

Guttilla, I. K., \& White, B. A. (2009). Coordinate regulation of FOXO1 by miR-27a, miR-96, and miR-182 in breast cancer cells. J Biol Chem, 284 (35), 23204-23216. doi:10.1074/jbc.M109.031427.

Wang S., Ai H., Liu L., Zhang X., Gao F., Zheng L., . . . Li Y. (2019). Micro-RNA-27a/b negatively regulates hepatic gluconeogenesis by targetingFOXO1.Am J Physiol Endocrinol Metab, 317(5): E911-e924.

Miao, Y., Kang, Z., Xu, F., Qi, S., Sheng, Y., Han, Y., . . . Yang, Q. (2013). Association analysis of the IL2RA gene with alopecia areata in a Chinese population. Dermatology, 227 (4), 299-304. doi:10.1159/000351555.

Xia, Z. L., Qin, Q. M., \& Zhao, Q. Y. (2018). A genetic link between CXCR5 and IL2RA gene polymorphisms and susceptibility to multiple sclerosis. Neurol Res, 40 (12), 1040-1047. doi:10.1080/01616412.2018.1517110.

Yun, X., Bai, Y., Li, Z., Wang, D., Zhu, Y., \& Jing, C. (2019). rs895819 in microRNA-27a increase stomach neoplasms risk in China: A meta-analysis. Gene, 707 , 103-108. doi:10.1016/j.gene.2019.04.061. 
Yu, H., Liu, Y., Bai, L., Kijlstra, A., \& Yang, P. (2014). Predisposition to Behcet's disease and VKH syndrome by genetic variants of miR-182. J Mol Med (Berl), 92 (9), 961-967. doi:10.1007/s00109-014-11599 .

Yu, H., Liu, Y., Zhang, L., Wu, L., Zheng, M., Cheng, L., . . . Yang, P. (2014). FoxO1 gene confers genetic predisposition to acute anterior uveitis with ankylosing spondylitis. Invest Ophthalmol Vis Sci, 55 (12), 7970-7974. doi:10.1167/iovs.14-15460.

Ma, J., Pei, Y., Xue, P., Wang, Y., Bao, X., \& Li, Y. (2019). Association of the polymorphisms in FOXO1 gene and diabetic nephropathy risk. Artif Cells Nanomed Biotechnol, 47 (1), 1471-1475. doi:10.1080/21691401.2019.1601103.

Ross, D. S., Burch, H. B., Cooper, D. S., Greenlee, M. C., Laurberg, P., Maia, A. L., . . . Walter, M. A. (2016). 2016 American Thyroid Association Guidelines for Diagnosis and Management of Hyperthyroidism and Other Causes of Thyrotoxicosis. Thyroid, 26 (10), 1343-1421. doi:10.1089/thy.2016.0229.

Sun, W., Zhang, X., Wu, J., Zhao, W., Zhao, S., \& Li, M. (2019). Correlation of TSHR and CTLA-4 Single Nucleotide Polymorphisms with Graves Disease. Int J Genomics, 2019 , 6982623. doi:10.1155/2019/6982623.

Kahaly, G. J., Diana, T., Kanitz, M., Frommer, L., \& Olivo, P. D. (2020). Prospective Trial of Functional Thyrotropin Receptor Antibodies in Graves Disease. J Clin Endocrinol Metab, 105 (4). doi:10.1210/clinem/dgz292.

Cerosaletti, K., Schneider, A., Schwedhelm, K., Frank, I., Tatum, M., Wei, S., . . . Long, S. A. (2013). Multiple autoimmune-associated variants confer decreased IL-2R signaling in CD4+ CD25(hi) T cells of type 1 diabetic and multiple sclerosis patients. PLoS ONE, 8 (12), e83811. doi:10.1371/journal.pone.0083811.

Ji, X., Wan, J., Chen, R., Wang, H., Huang, L., Wang, S., . . . Xu, H. (2020). Low frequency of IL-10producing B cells and high density of ILC2s contribute to the pathological process in Graves' disease, which may be related to elevated-TRAb levels. Autoimmunity, 53 (2), 78-85. doi:10.1080/08916934.2019.1698553.

Tang, W., Cui, D., Jiang, L., Zhao, L., Qian, W., Long, S. A., \& Xu, K. (2015). Association of common polymorphisms in the IL2RA gene with type 1 diabetes: evidence of 32,646 individuals from 10 independent studies.J Cell Mol Med, 19 (10), 2481-2488. doi:10.1111/jcmm.12642.

Song, Z. Y., Liu, W., Xue, L. Q., Pan, C. M., Wang, H. N., Gu, Z. H., . . . Song, H. D. (2013). Dense mapping of IL2RA shows no association with Graves' disease in Chinese Han population. Clin Endocrinol (Oxf), 79 (2), 267-274. doi:10.1111/cen.12115.

Buhelt, S., Sondergaard, H. B., Oturai, A., Ullum, H., von Essen, M. R., \& Sellebjerg, F. (2019). Relationship between Multiple Sclerosis-Associated IL2RA Risk Allele Variants and Circulating T Cell Phenotypes in Healthy Genotype-Selected Controls. Cells, 8 (6). doi:10.3390/cells8060634.

Chistiakov, D. A., Chistiakova, E. I., Voronova, N. V., Turakulov, R. I., \& Savost'anov, K. V. (2011). A variant of the Il2ra / Cd25 gene predisposing to graves' disease is associated with increased levels of soluble interleukin-2 receptor. Scand J Immunol, 74 (5), 496-501. doi:10.1111/j.1365-3083.2011.02608.x.

Brand, O. J., Lowe, C. E., Heward, J. M., Franklyn, J. A., Cooper, J. D., Todd, J. A., \& Gough, S. C. (2007). Association of the interleukin-2 receptor alpha (IL-2Ralpha)/CD25 gene region with Graves' disease using a multilocus test and tag SNPs. Clin Endocrinol (Oxf), 66 (4), 508-512. doi:10.1111/j.1365-2265.2007.02762.x.

He, J., Zhang, X., Wei, Y., Sun, X., Chen, Y., Deng, J., . . . Li, Z. (2016). Low-dose interleukin-2 treatment selectively modulates CD4(+) T cell subsets in patients with systemic lupus erythematosus. Nat Med, 22 (9), 991-993. doi:10.1038/nm.4148.

Viuff, M., Skakkebaek, A., Nielsen, M. M., Chang, S., \& Gravholt, C. H. (2019). Epigenetics and genomics in Turner syndrome. Am J Med Genet C Semin Med Genet, 181 (1), 68-75. doi:10.1002/ajmg.c.31683. 
Yang, J., Li, T., Gao, C., Lv, X., Liu, K., Song, H., . . . Xi, T. (2014). FOXO1 3'UTR functions as a ceRNA in repressing the metastases of breast cancer cells via regulating miRNA activity. FEBS Lett, 588 (17), 3218-3224. doi:10.1016/j.febslet.2014.07.003.

Strafella, C., Errichiello, V., Caputo, V., Aloe, G., Ricci, F., Cusumano, A., . . . Cascella, R. (2019). The Interplay between miRNA-Related Variants and Age-Related Macular Degeneration: EVIDENCE of Association of MIR146A and MIR27A. Int J Mol Sci, 20 (7). doi:10.3390/ijms20071578.

Takuse, Y., Watanabe, M., Inoue, N., Ozaki, R., Ohtsu, H., Saeki, M., . . . Iwatani, Y. (2017). Association of IL-10-Regulating MicroRNAs in Peripheral Blood Mononuclear Cells with the Pathogenesis of Autoimmune Thyroid Disease. Immunol Invest, 46 (6), 590-602. doi:10.1080/08820139.2017.1322975.

Du, Y. N., Tang, X. F., Xu, L., Chen, W. D., Gao, P. J., \& Han, W. Q. (2018). SGK1-FoxO1 Signaling Pathway Mediates Th17/Treg Imbalance and Target Organ Inflammation in Angiotensin II-Induced Hypertension.Front Physiol, 9 , 1581. doi:10.3389/fphys.2018.01581.

Gong, L., Li, R., Ren, W., Wang, Z., Wang, Z., Yang, M., \& Zhang, S. (2017). The FOXO1 Gene-Obesity Interaction Increases the Risk of Type 2 Diabetes Mellitus in a Chinese Han Population. J Korean Med Sci, 32 (2), 264-271. doi:10.3346/jkms.2017.32.2.264

\section{Table and Figure legends}

Table 1 Characteristics of GD patients and controls in this study.

Table 2 Association between IL2RA / rs3118470/ rs2104286 polymorphisms and GD susceptibility.

Table 3 Allele and genotype frequencies of three candidate gene loci and susceptibility to GO.

Figure 1 The IL2RA mRNA expression in anti-CD3/CD28 antibodies-stimulated PBMCs from healthy controls carrying various genotypes of rs2104286 (GG: $N=11, \mathrm{AG}: \mathrm{N}=12, \mathrm{AA}: \mathrm{N}=12$ ). The data are presented as the mean+-SD.

Figure 2 The influence of various rs3118470 genotypes on the IL-6 (A), IL-10 (B), IL-17(C) and TGF- $\beta 1(D)$ production (GG: $\mathrm{N}=12, \mathrm{AG}: \mathrm{N}=12$, $\mathrm{AA}: \mathrm{N}=12$ ). The production of cytokine was quantified by ELISA in PBMCs, which were obtained from healthy controls with various rs3118470genotypes and treated with antiCD3/CD28 antibodies.

Figure 3 The influence of various rs2104286 genotypes on the IL-6 (A), IL-10 (B), IL-17(C) and TGF- $\beta 1$ (D) production (GG: $\mathrm{N}=11, \mathrm{AG}: \mathrm{N}=12$, AA: $\mathrm{N}=12$ ). The production of cytokine was quantified by ELISA in PBMCs, which were obtained from healthy controls with various rs3118470 genotypes and treated with anti-CD3/CD28 antibodies.

Table S1 PCR primer sequences and reaction condition in this study.

Table S2 Association between remaining seven SNP polymorphisms and GD susceptibility.

Figure S1 The IL2RA mRNA expression difference with rs3118470 locus various genotype individuals.

Table 1 Characteristics of GD patients and controls in this study

\begin{tabular}{llll}
\hline Clinical characteristics & Frequency (\%) & Frequency (\%) & $P$ value \\
\hline & GD patients & Healthy controls & \\
Total $(\mathrm{N})$ & 650 & 1300 & - \\
Average age $[\mathrm{M} \pm \mathrm{SD}]$ & $38.8 \pm 14.7$ & $40.1 \pm 12.6$ & 0.574 \\
Male & $194(29.8)$ & $443(34.0)$ & - \\
Female & $456(70.2)$ & $857(66.0)$ & - \\
Ratio of male to female & $1: 2.35$ & $1: 1.93$ & 0.131 \\
\hline
\end{tabular}


Note: GD: Graves' disease; N: number; M: Mean value; SD: Standard Deviation.

Table 2 Association between IL2RA/rs3118470/ rs2104286 polymorphisms and GD susceptibility

\begin{tabular}{|c|c|c|c|c|c|c|c|}
\hline SNPs & Stage & $\begin{array}{l}\text { Allele } \\
\text { /Genotype }\end{array}$ & $\begin{array}{l}\text { GD pa- } \\
\text { tients }(\%)\end{array}$ & $\begin{array}{l}\text { Healthy } \\
\text { controls } \\
(\%)\end{array}$ & $P$ value & $P c$ value & $\begin{array}{l}\text { OR }(\mathbf{9 5 \%} \\
\mathrm{CI})\end{array}$ \\
\hline rs3118470 & First & $\mathrm{C}$ & $262(43.667)$ & $611(51.002)$ & 0.004 & NS & $\begin{array}{l}0.745(0.611- \\
0.907)\end{array}$ \\
\hline \multirow[t]{14}{*}{$(I L 2 R A)$} & & $\mathrm{T}$ & $338(56.333)$ & $587(48.998)$ & 0.004 & NS & $\begin{array}{l}1.343(1.103- \\
1.635)\end{array}$ \\
\hline & & $\mathrm{CC}$ & $72(24.000)$ & $165(27.546)$ & 0.262 & NS & $\begin{array}{l}0.831(0.603- \\
1.14)\end{array}$ \\
\hline & & $\mathrm{CT}$ & $118(39.333)$ & $281(46.912)$ & 0.033 & NS & $\begin{array}{l}0.734(0.554- \\
0.973)\end{array}$ \\
\hline & & $\mathrm{TT}$ & $110(36.667)$ & $153(25.543)$ & 0.001 & $0.027^{*}$ & $\begin{array}{l}1.688(1.253- \\
2.274)\end{array}$ \\
\hline & Second & $\mathrm{C}$ & $299(44.627)$ & $682(49.636)$ & 0.033 & NS & $\begin{array}{l}0.818(0.679- \\
0.984)\end{array}$ \\
\hline & & $\mathrm{T}$ & $371(55.373)$ & $692(50.364)$ & 0.033 & NS & $\begin{array}{l}1.223(1.016- \\
1.472)\end{array}$ \\
\hline & & $\mathrm{CC}$ & $69(20.597)$ & $177(25.764)$ & 0.070 & NS & $\begin{array}{l}0.747(0.545- \\
1.024)\end{array}$ \\
\hline & & $\mathrm{CT}$ & $161(48.060)$ & $328(47.744)$ & 0.924 & NS & $\begin{array}{l}1.013(0.780- \\
1.315)\end{array}$ \\
\hline & & $\mathrm{TT}$ & $105(31.343)$ & $182(26.492)$ & 0.105 & NS & $\begin{array}{l}1.267(0.951- \\
1.687)\end{array}$ \\
\hline & Combined & $\mathrm{C}$ & $561(44.173)$ & $1293(50.272)$ & $3.725 \times 10^{-4}$ & $1.490 \times 10^{-3}$ & $\begin{array}{l}0.783(0.684- \\
0.896)\end{array}$ \\
\hline & & $\mathrm{T}$ & $709(55.827)$ & $1279(49.728)$ & $3.725 \times 10^{-4}$ & $1.490 \times 10^{-3}$ & $\begin{array}{l}1.278(1.116- \\
1.462)\end{array}$ \\
\hline & & $\mathrm{CC}$ & $141(22.205)$ & $342(26.594)$ & 0.037 & NS & $\begin{array}{l}0.788(0.630- \\
0.986)\end{array}$ \\
\hline & & $\mathrm{CT}$ & $279(43.937)$ & $609(47.356)$ & 0.157 & NS & $\begin{array}{l}0.871(0.720- \\
1.055)\end{array}$ \\
\hline & & $\mathrm{TT}$ & $215(33.858)$ & $335(26.050)$ & $3.687 \times 10^{-4}$ & $2.212 \times 10^{-3}$ & $\begin{array}{l}1.453(1.182- \\
1.786)\end{array}$ \\
\hline rs2104286 & First & $\mathrm{A}$ & $505(84.167)$ & $952(79.333)$ & 0.015 & NS & $\begin{array}{l}1.385(1.068- \\
1.796)\end{array}$ \\
\hline \multirow[t]{6}{*}{$(I L 2 R A)$} & & G & $95(15.833)$ & $248(20.667)$ & 0.015 & NS & $\begin{array}{l}0.722(0.557- \\
0.936)\end{array}$ \\
\hline & & AA & $224(74.667)$ & $384(64.000)$ & 0.001 & $0.027^{*}$ & $\begin{array}{l}1.658(1.217- \\
2.258)\end{array}$ \\
\hline & & $\mathrm{AG}$ & $57(19.000)$ & 184(30.667) & $1.710 \times 10^{-4}$ & $4.617 \times 10^{-3^{*}}$ & $\begin{array}{l}0.530(0.379- \\
0.745)\end{array}$ \\
\hline & & GG & $19(6.333)$ & $32(5.333)$ & 0.543 & NS & $\begin{array}{l}1.200(0.668- \\
2.155)\end{array}$ \\
\hline & Second & $\mathrm{A}$ & $569(81.988)$ & $1094(78.143)$ & 0.040 & NS & $\begin{array}{l}1.273(1.010- \\
1.605)\end{array}$ \\
\hline & & G & $125(18.012)$ & $306(21.857)$ & 0.040 & NS & $\begin{array}{l}0.785(0.623- \\
0.990)\end{array}$ \\
\hline
\end{tabular}




\begin{tabular}{|c|c|c|c|c|c|c|c|}
\hline SNPs & Stage & $\begin{array}{l}\text { Allele } \\
\text { /Genotype }\end{array}$ & $\begin{array}{l}\text { GD pa- } \\
\text { tients }(\%)\end{array}$ & $\begin{array}{l}\text { Healthy } \\
\text { controls } \\
(\%)\end{array}$ & $P$ value & $P c$ value & $\begin{array}{l}\text { OR }(95 \% \\
\text { CI })\end{array}$ \\
\hline & \multirow{8}{*}{ Combined } & AA & $250(72.046)$ & $430(61.429)$ & 0.001 & 0.006 & $\begin{array}{l}1.618(1.224- \\
2.140)\end{array}$ \\
\hline & & $A G$ & $69(19.885)$ & 234(33.429) & $5.389 \times 10^{-6}$ & $3.233 \times 10^{-5}$ & $\begin{array}{l}0.494(0.364- \\
0.672)\end{array}$ \\
\hline & & GG & $28(8.069)$ & $36(5.143)$ & 0.063 & NS & $\begin{array}{l}1.619(0.971- \\
2.700)\end{array}$ \\
\hline & & A & $1074(82.998)$ & $2046(78.692)$ & 0.002 & 0.008 & $\begin{array}{l}1.322(1.112- \\
1.571)\end{array}$ \\
\hline & & G & $220(17.002)$ & $554(21.308)$ & 0.002 & 0.008 & $\begin{array}{l}0.757(0.636- \\
0.899)\end{array}$ \\
\hline & & AA & $474(73.261)$ & $814(62.615)$ & $2.924 \times 10^{-6}$ & $1.754 \times 10^{-5}$ & $\begin{array}{l}1.636(1.330- \\
2.012)\end{array}$ \\
\hline & & $\mathrm{AG}$ & $126(19.474)$ & $418(32.154)$ & $4.274 \times 10^{-9}$ & $2.564 \times 10^{-8}$ & $\begin{array}{l}0.510(0.407- \\
0.640)\end{array}$ \\
\hline & & GG & $47(7.264)$ & $68(5.230)$ & 0.073 & NS & $\begin{array}{l}1.419(0.966- \\
2.084)\end{array}$ \\
\hline
\end{tabular}

Note: GD: Graves' disease; SNPs: Single nucleotide polymorphisms; Pc, Bonferroni corrected p value; OR: Odds ratio; $95 \% \mathrm{Cl}$ : $95 \%$ Confidence Level; NS, not significant.

Table 3 Allele and genotype frequencies of two candidate gene loci and susceptibility to GO

\begin{tabular}{|c|c|c|c|c|c|c|}
\hline SNPs (Gene) & $\begin{array}{l}\text { Allele } \\
\text { /Genotype }\end{array}$ & GO patients & $\begin{array}{l}\text { Healthy } \\
\text { controls }\end{array}$ & $P$ Value & $P c$ Value & $O R(\mathbf{9 5 \%} \mathbf{C I})$ \\
\hline & & $n=205$ & $n=1300$ & & & \\
\hline rs3118470 & $\mathrm{C}$ & $158(38.537)$ & $1293(50.272)$ & $1.009 \times 10^{-5}$ & $4.036 \times 10^{-4}$ & $\begin{array}{l}0.620(0.501- \\
0.768)\end{array}$ \\
\hline \multirow[t]{4}{*}{$(I L 2 R A)$} & $\mathrm{T}$ & $252(61.463)$ & $1279(49.728)$ & $1.009 \times 10^{-5}$ & $4.036 \times 10^{-4}$ & $\begin{array}{l}1.612(1.303- \\
1.996)\end{array}$ \\
\hline & $\mathrm{CC}$ & $42(20.488)$ & $342(26.594)$ & 0.063 & NS & $\begin{array}{l}0.711(0.496- \\
1.020)\end{array}$ \\
\hline & $\mathrm{CT}$ & $74(36.098)$ & $609(47.356)$ & 0.003 & 0.018 & $\begin{array}{l}0.628(0.463- \\
0.852)\end{array}$ \\
\hline & $\mathrm{TT}$ & $89(43.415)$ & $335(26.050)$ & $3.080 \times 10^{-7}$ & $1.848 \times 10^{-6}$ & $\begin{array}{l}2.178(1.609- \\
2.949)\end{array}$ \\
\hline rs2104286 & $\mathrm{A}$ & $339(82.683)$ & $2046(78.692)$ & 0.064 & NS & $\begin{array}{l}1.293(0.984- \\
1.698)\end{array}$ \\
\hline \multirow[t]{4}{*}{$(I L 2 R A)$} & $\mathrm{G}$ & $71(17.317)$ & $554(21.308)$ & 0.064 & NS & $\begin{array}{l}0.773(0.589- \\
1.016)\end{array}$ \\
\hline & $\mathrm{AA}$ & $155(75.610)$ & $814(62.615)$ & $2.050 \times 10^{-4}$ & $1.230 \times 10^{-3}$ & $\begin{array}{l}1.851(1.320- \\
2.595)\end{array}$ \\
\hline & $\mathrm{AG}$ & $29(14.146)$ & $418(32.154)$ & $1.570 \times 10^{-7}$ & $9.420 \times 10^{-6}$ & $\begin{array}{l}0.348(0.231- \\
0.524)\end{array}$ \\
\hline & GG & $21(10.244)$ & $68(5.230)$ & 0.005 & 0.030 & $\begin{array}{l}2.068(1.238- \\
3.455)\end{array}$ \\
\hline
\end{tabular}


Note: GO: Graves' ophthalmopathy; SNPs: Single nucleotide polymorphisms; A: Allele; G: Genotype; Pc, Bonferroni corrected p value; OR: Odds ratio; 95\% Cl: 95\% Confidence Level; NS, not significant.

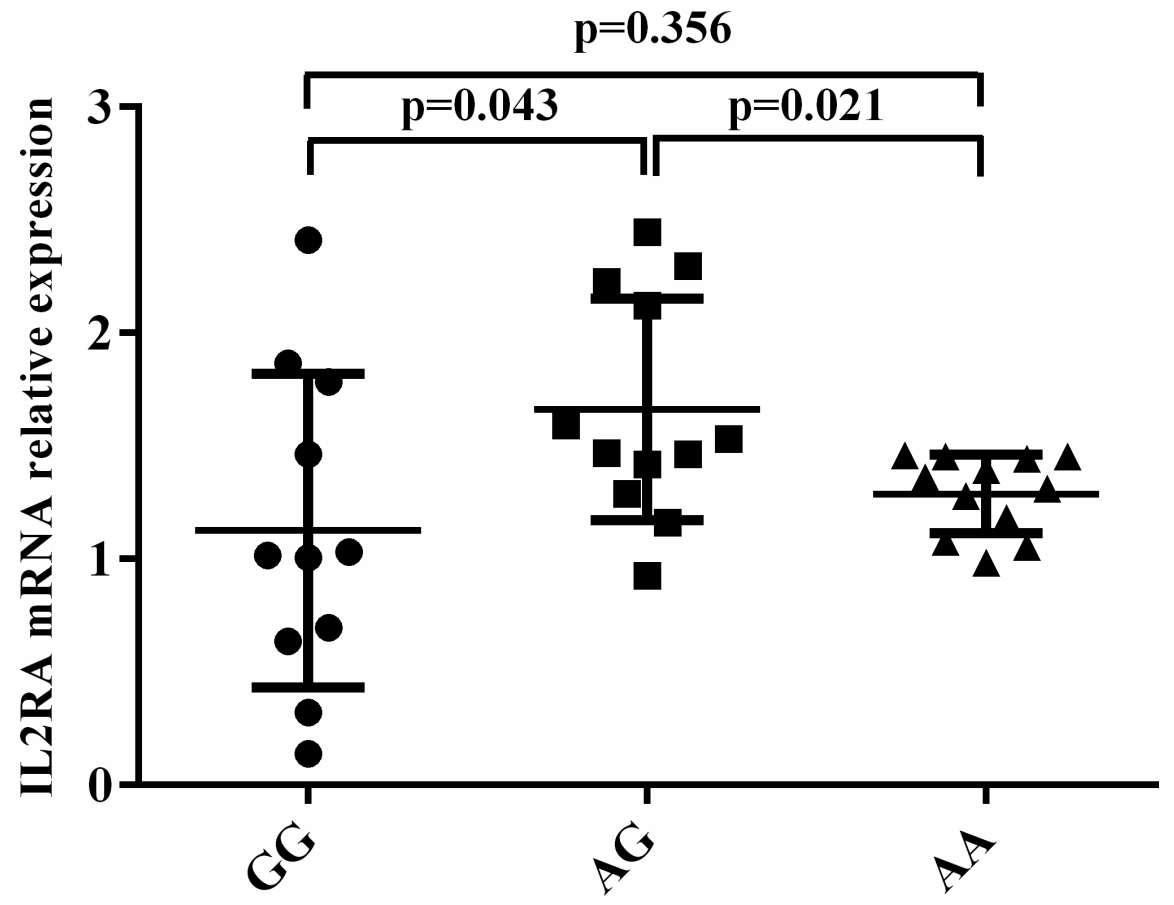

A

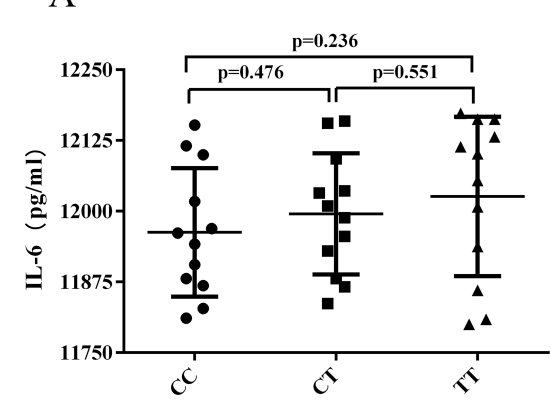

$\mathrm{C}$

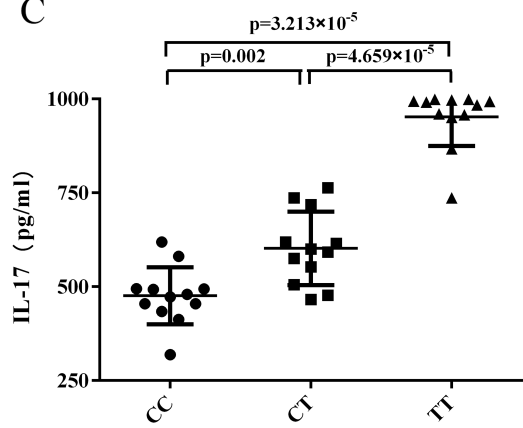

$\mathrm{B}$

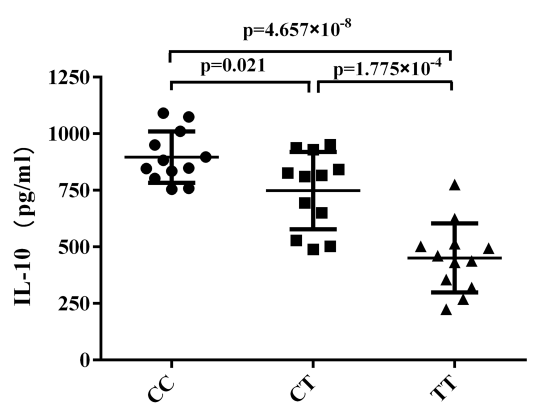

$\mathrm{D}$

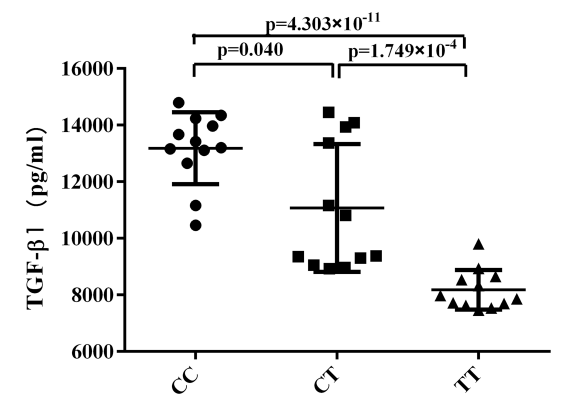



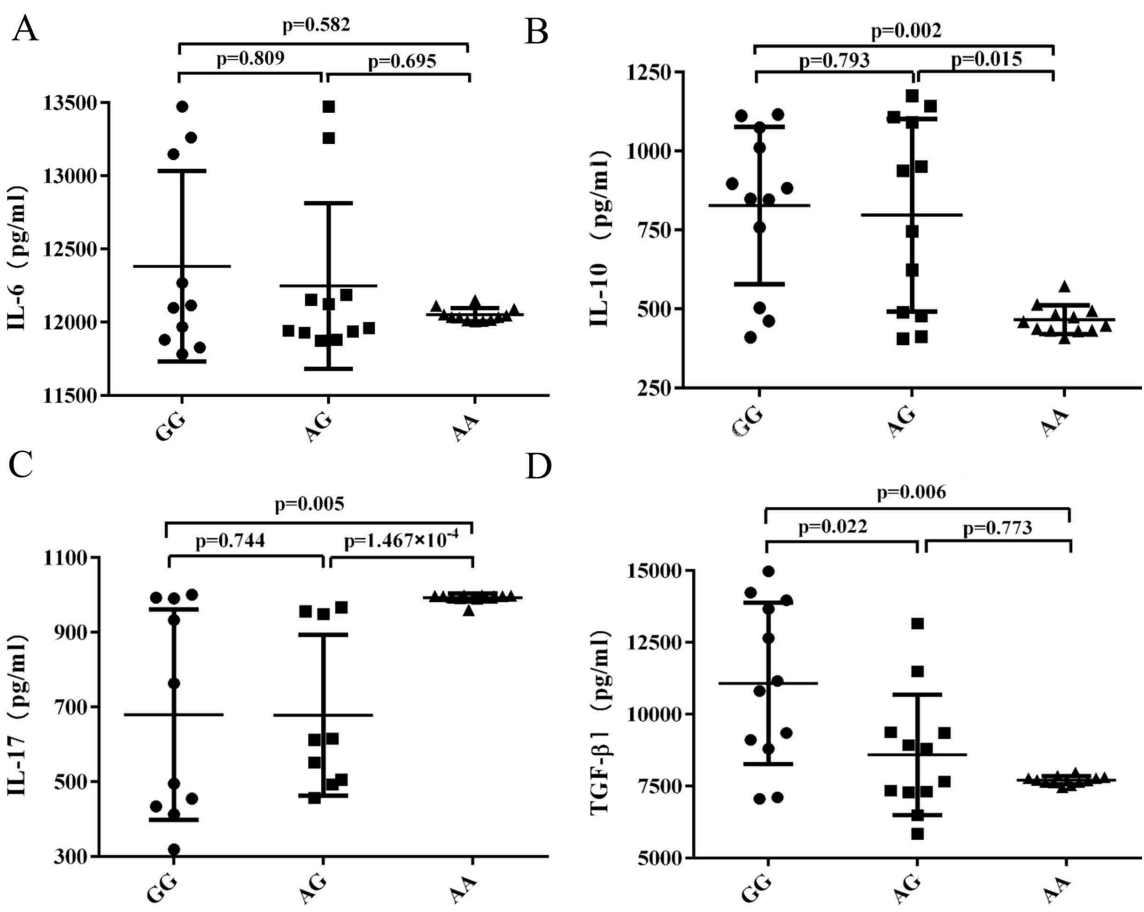